\title{
Straddling the Divide: Towards an Associate Degree in Information Technology
}

\author{
Grace Tan \\ Victoria University, Melbourne, Victoria, Australia
}

Grace.Tan@vu.edu.au

\section{Executive Summary}

Governments recognize that workers in the twenty-first century need to keep pace with increasingly technical employment environments in order to remain competitive in the global market. The Australian government has developed a set of policies to address impending shortfalls in high-level technicians and paraprofessionals across many professions. As a result, a new fledgling qualification, the associate degree, has been established within the Australian Qualifications Framework (AQF) to facilitate qualification upgrading for the existing workforce.

This paper describes Australian associate degrees and highlights their similarities and differences to foundation degrees in the United Kingdom and associate degrees in the United States. In Australia, universities and higher education (HE) institutes have limited experiences catering to vocational training, since vocational education (VE) has been reserved for specialist technical and further education (TAFE) colleges. Interestingly, the AQF intends that associate degree qualifications can cut across sectors.

This discussion paper details the development of an associate degree in information technology (IT) at Victoria University, where two education sectors, one vocationally-focused and one academically-focused, are collaborating to effect the degree. Eight areas of competency are identified as needed by graduates of the proposed IT program. Two models for the cooperation in curriculum development are proposed. Regardless of the model chosen, the collaboration provides the opportunity for the achievement of a program that would dovetail vocational skills with supporting academic competencies to meet the needs of information technology workers wishing to upskill. Under discussion are issues such as staffing and administration, program sustainability and context of delivery, industry partnerships, and their impact upon differing cohorts of students with variability in experience.

Keywords: associate degrees, curriculum development, foundation degrees, vocational training, higher education.

Material published as part of this publication, either on-line or in print, is copyrighted by the Informing Science Institute. Permission to make digital or paper copy of part or all of these works for personal or classroom use is granted without fee provided that the copies are not made or distributed for profit or commercial advantage AND that copies 1) bear this notice in full and 2) give the full citation on the first page. It is permissible to abstract these works so long as credit is given. To copy in all other cases or to republish or to post on a server or to redistribute to lists requires specific permission and payment of a fee. Contact Publisher@InformingScience.org to request redistribution permission.

\section{Introduction}

In response to global economic competition and the need to increase workforce skill levels, there has been a push for the systematic development of paraprofessional qualification programs internationally (Robertson, 2002). Brown and Hesketh (2004) forecasted that $78 \%$ of jobs in the U.K. and the U.S. by 2010 
would require additional training, ranging from on-the-job to associate/professional, to increase overall productivity. The importance of having a population with high-level skills has been widely recognized by most countries. As a result, sub-degrees or intermediate qualifications of one sort or another can be found in France, Germany, Australia, U.K., and the U.S. (Department for Education and Employment, 2000; HEFCE, 2000; Levey, 1998; Wilson, Blewitt, \& Moody, 2005).

In Australia, the Government has identified impending shortfalls in the numbers of technicians and paraprofessionals. To secure long-term economic prosperity and to build capacity, Australia has moved to develop a set of policies to facilitate qualification upgrading for the existing workforce (Australian Government, 2008). Drafting these policies has been an impetus to crossexamine the traditional, government-sponsored post secondary education offerings and their shortcomings in addressing the need to up-skill the existing workforce. The publicly funded tertiary qualifications offered in the vocational education and training (VET) sector has a very different focus than that offered by the higher education (HE) sector. While VET provides skills and knowledge for work, HE provides programs that are more academically oriented. Conventionally, for those wishing to upgrade their skills, further vocational training had been accessed through a variety of routes, product vendors, private training centres and professional bodies.

In 2002, the Australian Qualifications Framework (AQF) established a new qualification titled the associate degree. Situated within the higher education structure, the associate degree is a twoyear post-secondary qualification integrating generic and employment-related skills, with a single or multidisciplinary discipline focus. By situation within the AQF, a learner in the study of an associate degree program is entitled to a government funded place. The attachment of government funding support helps legitimatize this new qualification in the eyes of the public.

\section{Australian Associate Degrees}

Internationally, a great variety of two-year, intermediate, paraprofessional and sub-degree qualifications are available. In the U.K., over 2000 foundation degrees were delivered to over 38,000 students during 2007 (McCormack, 2007). According to Wilson et al. (2005) in their observations of the systems in the U.S., students have various associate degree options, including those offered by community colleges, junior colleges, and universities. These associate degrees attracted large cohorts of students and 11.3 million had graduated by 2000. A major benefit of these degree programs is that of social inclusion (Department for Education and Skills, 2003; Wilson et al., 2005). Historically, they have widened participation in higher education for students with non-traditional backgrounds such as immigrants, older workers particularly women, midlife career changers, and minority groups.

Despite the similarity in name to American associate degrees, the intent of Australian associate degrees is not, first and foremost, to be a funnel to higher education studies. Rather, it is somewhat closer to the philosophy of the English foundation degrees where studies are closely aligned to address workforce mid-level skill shortages. Australian associate degrees provide a broad-base point-of-entry to employment with learning outcomes for graduates being the acquisition of foundational underpinnings of one or more disciplines, the development of generic employmentrelated skills, the development of academic skills and attributes, and the capacity for self-directed and lifelong learning (Australian Qualifications Framework, 2007). Australian associate degrees are to be vocational in nature, reliant on a close collaboration between employers and educational providers to affect the qualification. The relative position of the associate degree to other qualifications is shown in Figure 1. It is important to note that direct comparisons between qualifications from different sectors are not easily made, as these qualifications recognize different types of learning reflecting the distinctive educational responsibilities of each sector. 


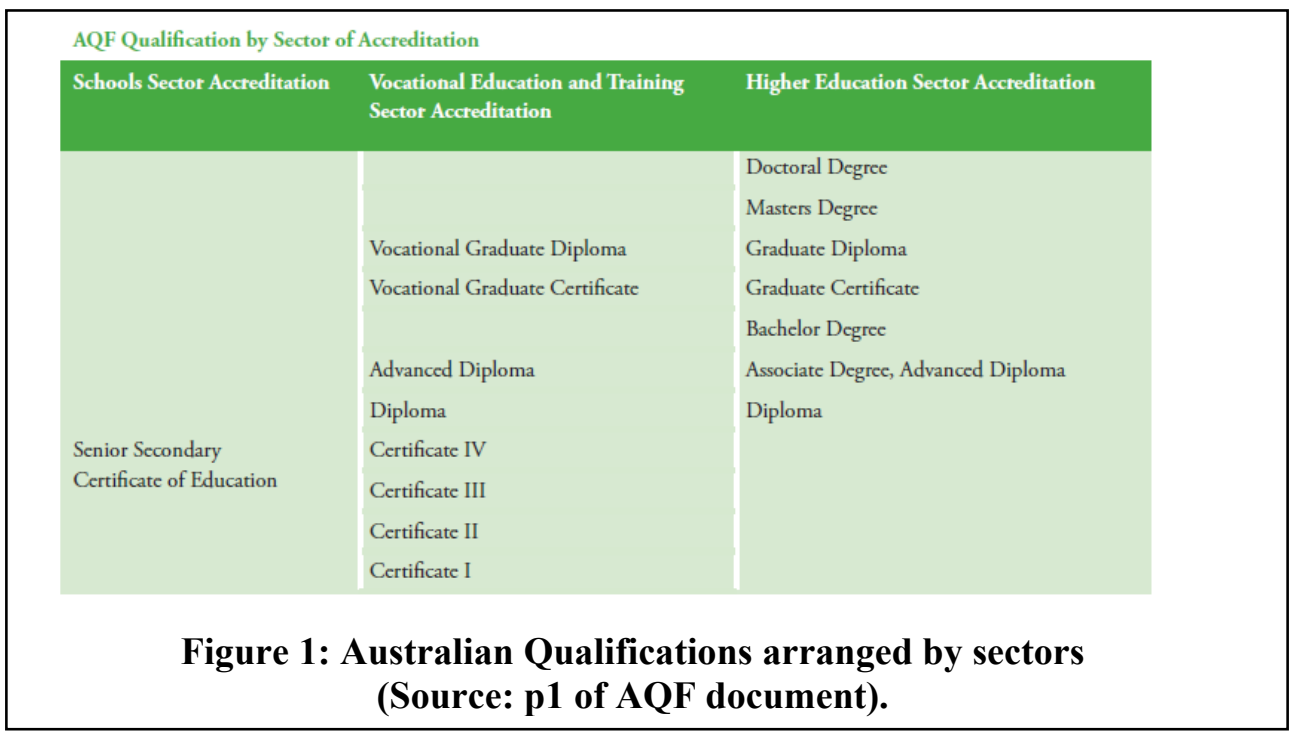

Typically in Australia, universities and other higher education (HE) institutes have limited experience catering to vocational training. Particularly in the technical sciences, vocational education (VE) has been the domain for specialist technical and further education (TAFE) colleges. The new associate degree is one of few cross-sectoral qualifications within the Australian Qualification Framework that can be delivered via either TAFE colleges or universities. The only stipulation of the AQF is that the qualification needs to be conferred by a HE provider. This requirement can create tensions between the two sectors, VE and HE, since both are vying for government funding for associate degrees.

An observer surveying the pre-associate degree higher education landscape in Australia may be struck by the magnitude of each of the monolithic VE and HE encampments. VE and HE are structurally separated by a philosophical divide across which they have entirely different 'modus operandi' and 'world views'. The divide is apparent in the way each group derives its sources of funding; organizes its contracts of employment; balances the importance between teaching, administration, and research; sets its academic calendar; and assigns holiday entitlements. These alternate ways of operating, create a 'difference in understanding' chasm that needs to be bridged before any meaningful dialogue can commence between both camps regarding the development of a joint educational qualification. Thus, any dual sector institutes, those housing separate TAFE and university components, are strategically placed to initiate conversation with the view to collaboration in associate degree development. These dual sector institutes can avail themselves of new funding opportunities through the implementation of the qualification.

\section{Associate Degrees @ Victoria University}

Victoria University is a dual sector university that currently caters to 50,000 on and off-campus students. Students study in programs ranging from technical certificates to the Ph.D. level, in courses as diverse as microelectronics and sports physiology. Over $20 \%$ of the student body comes from a low socioeconomic status and the University is located in the traditionally working class western region of Melbourne. Despite the disadvantages of many of its students, the University seeks to provide students with a range of choices within programs to ensure good graduate outcomes without sacrificing overall academic excellence.

As the second largest employer within the region, Victoria University has a long history of workfocused learning. For its academic programs, it actively seeks engagement with and support from local industries. Therefore, as a cross-sectoral qualification, the associate degree opens many new 
opportunities. For the university, the identification and development of various associate degree programs offers exciting opportunities to encourage and embed cross-sectoral collaborations. For students, associate degree programs offer strong vocational training allied with technical underpinnings and the possibility to articulate to higher degree programs.

The University requires that both the VE and HE sectors contribute to the production and delivery of a curriculum, emphasizing that an associate degree is an entity unto itself and not a sub-degree. To this effect, the University developed a generic associate degree template to guide educators. The purpose of the template is to provide a framework to ensure coherence, standardized governance and management rules, and consistency within programs. In summary, the associate degree generic framework is designed to underpin all development efforts and to actively stimulate cross-fertilizations between both education sectors.

An early success story of this approach has been the Associate Degree in Culinary Management. The program is a partnership between the Paris-based culinary group Le Cordon Bleu School and Victoria University to train students in practical hospitality skills while they are learning underlying theory. Essentially, students study both HE and VE content throughout the entire four semesters of their program. Already, the program is being hailed as an Australian exemplar of seamless and blended provision of vocational and academic educational services.

Motivated by the success of the Associate Degree in Culinary Management and identifying a market need for up-skilling information technology workers, interested parties from TAFE and HE came together to explore the potential of an Associate Degree in Information Technology (IT) across sectors within Victoria University. The discussion identified the needs of prospective students who are aiming to be promoted within their organizations, such as low skill IT workers. To develop these skills, workers need a program dovetailing vocational skills with supporting academic competencies.

\section{Associate Degree in IT Proposal}

One of the major commitments of associate degrees is to provide programs that are workplace relevant. To this end, the program should incorporate a strong industry-based learning component within the curriculum (Brennan, 2005; Stinton, 2007). For instance, a tailored program in the Foundation Degree in Applied Technology designed by Staffordshire University for one of the largest privately-owned companies in the U.K. is an excellent example of a foundation degree program developed in response to workforce development (Benefer, 2007).

Like British foundation degrees, Australian associate degrees are to be developed for niche markets to meet specific occupational needs. In this case, the demand for credentialed mid-level IT professionals instigated the search for a suitable curriculum for an Associate Degree in IT at Victoria University. To begin the discussion, VE educators from the School of IT met with HE academics from the School of Engineering and Science and the School of Management and Information Systems. Amongst the VE and HE participants consensus was reached that, collectively, the group had the desire and necessary resources to address the skill gaps for this cohort of students. Further discussion was needed to flesh out the most appropriate curriculum model for an associate degree in IT.

At the program development meeting, it was acknowledged that there are historical dissonances in course design and instruction, assessment methods, types of learners and funding between the parties to overcome. The program must draw on the content and delivery strengths of both sectors, yet the mechanism allowing this married delivery still needed to be decided by the program development team. For most, the generic framework for associate degrees proposed by the University provided a suitable structure to straddle the philosophical gap between the sectors. 
In deciding the nature of the associate degree program, several alternate models of delivery were considered. Students need to complete 16 units of study over a two-year period to achieve an associate degree. It was agreed that, for equal ownership, 50\% of program content should be delivered by VE and 50\% by HE. An incremental approach over the total of 16 units of study in the program was proposed and is shown in Table 1. In the first of four semesters, learners are able to acquire mostly vocational learning through VE units with an introduction to a higher education studies, through to a final semester where academic HE units will be in the majority. Such a mode is staged to allow learners to gradually acquire the academic foundational underpinnings of a discipline together with opportunities for experiential, vocational learning.

Table 1: Proposed structure of the Associate Degree in IT at Victoria University, where shading indicates higher education sector teaching responsibilities

\begin{tabular}{|l|l|l|l|l|l|l|l|l|}
\hline & \multicolumn{4}{|c|}{ Semester 1 } & \multicolumn{4}{c|}{ Semester 2 } \\
\hline Year 1 & VE 1 & VE 2 & VE 3 & HE 1 & VE 4 & VE 5 & HE 2 & HE 3 \\
\hline Year 2 & VE 6 & VE 7 & HE 4 & HE 5 & VE 8 & HE 6 & HE 7 & HE 8 \\
\hline
\end{tabular}

In attempting to flesh out the proposed framework with suitable units of study, it was important to identify the competencies needed by graduates of the proposed Associate Degree in IT program. It was recognized that these competencies are of two distinct types: those that are broader and more generic employment-related skills and others that are specific discipline-related proficiencies. The competencies identified by members of the discussion group as suitable for the associate degree are listed in Table 2.

Table 2: Area of competencies in the proposed structure of the Associate Degree in IT at Victoria University

\begin{tabular}{|l|}
\hline General Competencies \\
\hline Business Analysis \\
\hline IT Services Management \\
\hline Information Systems \\
\hline Report Writing \\
\hline Specific Competencies \\
\hline Database Design \& Queries \\
\hline Database Management \& Administration \\
\hline Web-database Connectivity \\
\hline Workplace Project \\
\hline
\end{tabular}

It was decided that each of the competencies in Table 2 should be taught in their entirety through two units of study. This arrangement of two units per eight competencies would map to the sixteen unit framework shown in Table 1. Once this arrangement had been agreed upon, the division of the teaching responsibilities for each sector needed to be decided. Keeping within the intent 
that the Associate Degree in IT is a cross-sectoral offering, two distinct models were proposed for the program. Each is outlined in the Discussion following.

\section{Discussion}

In both models, the eight areas of competency are divided equally between the vocational education (VE) and the higher education (HE) areas of the University. However, the manner in which this is to be accomplished is entirely different in each case. In Model A, four competencies are identified and assigned to VE and the remaining four are assigned to HE as shown in Table 3. There is a deliberate attempt to equally share the general competencies and the specific competences between both sectors with a view to harness each of their historical strengths and differing teaching styles.

Table 3: Model A showing teaching responsibilities of competencies by sector where

\section{$\checkmark$ signifies participation}

\begin{tabular}{|l|c|c|}
\hline & VE & HE \\
\hline General Competencies & & \\
\hline Business Analysis & $\checkmark$ & \\
\hline IT Services Management & $\checkmark$ & \\
\hline Information Systems & & $\checkmark$ \\
\hline Report Writing & & $\checkmark$ \\
\hline Specific Competencies & $\checkmark$ & \\
\hline Web-database Connectivity & $\checkmark$ & \\
\hline Database Design \& Queries & & $\checkmark$ \\
\hline Database Management \& Administration & & $\checkmark$ \\
\hline Workplace Project & & \\
\hline
\end{tabular}

One of the major advantages of the Model A approach is in the delineation of teaching tasks and responsibilities which can be defined for each sector. This separation allows both VE and HE to independently assign the necessary resources for the development and delivery of $50 \%$ of the associate degree with clearly defined curriculum responsibilities. For each competency, either general or specific, there are two units of study. There needs to be consistency in content development and assessment practices across the two units. For students studying in a joint program, this consistency within topics helps to cushion student transition issues.

One major disadvantage of Model A is in the way that all parties, including students, HE, and VE, will view the award. The temptation will be to see the associate degree as a mere amalgamation of disjointed parts from other diplomas or degree programs, instead of a unique and separate qualification in its own right. To avoid this problem, a second model, Model B, was proposed. In this model, the responsibility for each and every competency is shared equally by both sectors. VE is responsible for the introduction of each proficiency in a single unit of study and the advanced unit of study for the same competency will be delivered by HE, as shown in Table 4. 
Table 4: Model B showing equally shared teaching responsibilities of competencies where $\checkmark$ signifies participation.

\begin{tabular}{|l|c|c|}
\hline & VE & HE \\
\hline General Competencies & & \\
\hline Business Analysis & $\checkmark$ & $\checkmark$ \\
\hline IT Services Management & $\checkmark$ & $\checkmark$ \\
\hline Information Systems & $\checkmark$ & $\checkmark$ \\
\hline Report Writing & $\checkmark$ & $\checkmark$ \\
\hline Specific Competencies & $\checkmark$ & $\checkmark$ \\
\hline Web-database Connectivity & $\checkmark$ & $\checkmark$ \\
\hline Database Design \& Queries & $\checkmark$ & $\checkmark$ \\
\hline Database Management \& Administration & $\checkmark$ & $\checkmark$ \\
\hline Workplace Project & & \\
\hline
\end{tabular}

The major advantage of Model B is that it is evident to all parties that VE is responsible for the elementary and vocational underpinnings of the program and that HE is responsible for the further development of each competency and the distillation of the academic content. This consistent approach across each of the eight competencies underlines the inherent link between theory and paraprofessional practice.

The major disadvantage of Model B is the necessity of ensuring a coherent and consistent design of the associate degree across both sectors. It is reliant on a genuine collaboration between both HE and VE groups. Given sufficient goodwill between the parties, considerable overheads in resources and time will be needed to ensure a smooth integration of topics from the elementary to advanced units within each competency of the proposed program. Lessons learned from successful foundation degrees in the U.K. show that all partners to these programs need to "have complementary aims, compatible missions, good personal relationships, clear responsibilities, trust each other, and are prepared to sign up to a common agreement on respective roles and commitments" (Benefer, 2007). As this paper is being written, dialogue continues about the best way to divide the curriculum for the proposed Associate Degree in IT. This cross-sectoral qualification will pose numerous challenges for the program development team across the two sectors in deriving a cohesive program.

Irrespective of the model that is eventually chosen, there are a number of important issues that will need to be addressed. As mentioned by Hillier and Rawnsley (2006) in the U.K., some issues include the variability of student experience, the nature of relationship between stakeholders and stakeholder perspectives on learning aims, and the extent of any employer involvement. Stinton (2007) reported that successful U.K. programs are identifiable by strong employer engagement. In particular, he reported "the maximum and most effective employer engagement appeared to be in course design, minimal involvement was reported with assessment." Stinton further recommends that a cohesive partnership be fostered between employers and educators, so the engagement with workplaces will be an important issue for development in the Associate Degree in IT, where it is envisioned that workplace projects will be an essential capstone component. Therefore, the identification of suitable industry partners will be pivotal in deciding the overall sustain- 
ability of the proposed program. Another important issue for consideration is the context of delivery to further bolster the student learning experience and promote professionalism. The identification of relevant industry certificates and the extent to which vendor certification is to be undertaken is yet to be resolved.

Resolving these key issues and deciding where the governance of quality resides over the program will be a major task for the course proponent team. The University's associate degree generic framework offers broad guidance but gives little specific direction. This lack of detail allows considerable flexibility for implementation. So over the coming months, work will be undertaken by both sectors in deciding the most appropriate model to be adopted, the fleshing out of unit outlines, the pedagogy, and modes of deliveries, and securing suitable industry partnerships.

Regardless of the specific implementation details, the introduction of the associate degree qualification will provide a new opportunity for existing workers who wish to up-skill to engage with the University on their own educational journeys. Through the recognition of existing skills, the program will allow this new cohort to fill gaps in their workplace knowledge and gain new proficiencies for roles for which there were no existing qualifications previously (Edmond, Hillier, \& Price, 2007). As a government recognized and funded qualification, the Associate Degree in IT brings legitimacy through academic validation and workplace recognition.

\section{References}

Australian Government. (2008). Review of Australian higher education final report. Retrieved November 2009 from report, http://www.deewr.gov.au/HigherEducation/Review/Documents/PDF/Higher\%20Education\%20Revie w_one $\% 20$ document_02.pdf

Australian Qualifications Framework. (2007). Australian qualifications framework implementation handbook (4th ed.). Retrieved November 2009 from http://www.aqf.edu.au/Portals/0/Documents/Handbook/AQF_Handbook_07.pdf

Benefer, R. (2007). Engaging with employers in work-based learning: A foundation degree in applied technology. Education + Training, 49(3), 210-217.

Brown, P., \& Hesketh, A. (2004). The mismanagement of talent: Employability and jobs in the knowledge economy. Oxford University Press.

Brennan, L. (2005). Integrating work-based learning into higher education. A guide to good practice, Bolton, University Vocational Awards Council.

Department for Education and Employment. (2000). Foundation degrees: Consultation paper. DfEE, London.

Department for Education and Skills. (2003). Widening participation in higher education. HMSO, London.

Edmond, N., Hillier, Y., \& Price, M. (2007). Between a rock and a hard place, the role of HE and foundation degrees in workforce development. Education + Training, 49(3), 170-181.

HEFCE. (2000). Foundation degree prospectus: Invitation (00/27). Higher Education Funding Council for England, Bristol.

Hillier, Y., \& Rawnsley, T. (2006). Education, education, education or employers, education and equity: Managing employer and employee expectations of foundation degrees. Proceedings of Higher Education Close Up Conference, University of Lancaster, 24-26 July, 2006.

Levey, F. (1998). The new dollars and dreams: American incomes and economic change. New York, NY: Russell Sage.

McCormack, J. (2007). Foundation degrees in the U.K. @ 2007. An internal Victoria University report. 
Robertson, D. (2002). Intermediate level qualifications in higher education - An international assessment. HEFCE, Bristol. Retrieved November 2009 from http://www.hefce.ac.uk/pubs/rdreports/2002/rd10_02/

Stinton, J. (2007). Employer engagement in the design, development and delivery of foundation degrees in the eastern region. The Research and Development Bulletin, 5(2), 27-32.

Wilson, J. P., Blewitt, J., \& Moody, D. (2005). Reconfiguring higher education: The case of foundation degrees. Education + Training, 47(2), 112-123. Emerald Group Publishing Limited.

\section{Biography}

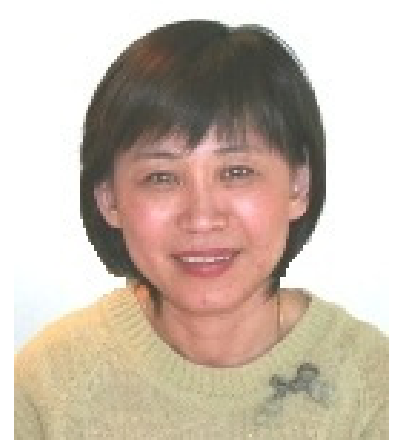

Grace Tan is a senior lecturer in Computer Science at Victoria University, Melbourne, Australia. Her research interests include investigations of innovative teaching methods, the development of graduate attributes, and issues related to female students in computing courses and Grace has published in these areas. 